\title{
THE CORRELATION BETWEEN DISEASE ACTIVITY ASSESSED BY DAS28-ESR AND QUALITY OF LIFE ASSESSED BY SF-36 IN RHEUMATOID ARTHRITIS PATIENTS
}

\author{
Putri Vidyaniati $^{1}$, Rachmat Gunadi Wachjudi ${ }^{1}$, Anna Tjandrawati ${ }^{2}$, Laniyati Hamijoyo ${ }^{1}$ \\ ${ }^{1}$ Rheumatology Division, Department of Internal Medicine, Faculty of Medicine, Padjadjaran University, Hasan Sadikin Hospital \\ ${ }^{2}$ Department of Clinical Pathology, Faculty of Medicine, Padjadjaran University, Hasan Sadikin Hospital
}

\section{A R T I C L E I N F O}

\section{Keywords:}

Disease Activity

Rheumatoid Arthritis

Quality of Life

\section{Corresponding author: \\ Putri Vidyaniati \\ E-mail address:

p.vidyaniati@gmail.com

All authors have reviewed and approved the final version of the manuscript.

https://doi.org/ 10.37275/IJR.v10i1.1

\begin{abstract}
A B S T R A C T
Background Rheumatoid arthritis is the most prevalent form of inflammatory arthritis. One of the key components for its multidimensional outcome is the disease activity, measured by DAS28-ESR. The physical, emotional, and social aspects of RA contribute to the quality of life, and SF-36 questionnaire can be used to measure it. This study aims to ascertain the correlation between the disease activity (DAS28-ESR) and the quality of life (SF-36) in RA patients. Method This study was an analytical, descriptive study with a cross sectional design that took primary data from RA patients undergoing treatment in Rheumatology Clinic of Hasan Sadikin Hospital from February to May 2015. The patient's data included sex, age, marital status, employment status, educational level, serostatus (RF and Anti-MCV), duration of diagnosis, total number of medications, total number of DMARD, DAS28-ESR scores, and SF-36 scores. The data was analysed with the Shapiro-Wilk normality test, followed by the Rank-Spearman correlation analysis. Result There were 42 subjects, with an average age of $41 \pm 12$. The ratio between females and males was $20: 1$, and the majority of subjects $(73.8 \%)$ had a positive serostatus (RF and/or anti-MCV). The median score of DAS28-ESR was 4.3, while the median score for SF-36 PCS being 39.8 and the median score for SF-36 MCS was 48.2. Based on the the Rank-Spearman analysis (CI of 95\%), there was a correlation between DAS28-ESR score and SF-36 PCS score, with the correlation coefficient ( $r$ ) of $0.577(\mathrm{p}<0.001)$, also there was a correlation between DAS28-ESR score and SF-36 MCS score with $\mathrm{r}$ of $-0.368(\mathrm{p}=0.008)$. Conclusion There was a strong negative correlation between disease activity and physical component of quality of life, and a moderate negative correlation between disease activity and mental component of quality of life, and the two correlations were statistically significant.
\end{abstract}

\section{Introduction}

Rheumatoid arthritis (RA) is the most prevalent form of inflammatory arthritis, with a prevalence of 0.5 - 1\% around the world.1,2 This disease can occur at any age, but the patients most affected are those in the third to sixth decade of their lives, which is a productive period of age. ${ }^{3}$ Data from Indonesia Basic Health Research (2007) and National Economic Social Survey (2007) showed that the prevalence in Indonesia was around $0.1 \% .{ }^{4}$ Even though this degree of prevalence is considered low, this disease is associated with many extra-articular and systemic complications that can lead to pain and disability as well as emotional, social, and economic problems. ${ }^{5}$ The mortality rate of the patients is also higher than that of the general population. 6

The outcome in quality of life is considered to be a more important aspect in the management of RA, ${ }^{14}$ as the physical, emotional, and social aspects of RA contribute to the patients' low quality of life. ${ }^{5}$ Based on a systematic review by Karimi et al. (2013), one of the factors that affects the quality of life is disease 
activity. ${ }^{15}$ A study result by Lu et al. (2008) showed a moderate-strong correlation between disease activity and the physical and mental components of quality of life. ${ }^{16}$ A different result occurred in a study by Kojima et al. (2008), where the correlation was only weakmoderate, and the disease activity was independent from psychosocial factors, and did not reflect the physical and mental components of quality of life in RA patients. 17 Another study by Radner et al. (2014) showed that disease activity only significantly correlated with the physical component of quality of life, not the mental component of quality of life. ${ }^{9}$

There are several methods to assess quality of life, and the easiest and cheapest is a self-administered questionnaire by the patients. ${ }^{18}$ The Short Form 36item Health Survey Questionnaire (SF-36) is an example of a generic questionnaire most often used to evaluate quality of life as a subjective perception of psychological and physical limitations caused by the musculoskeletal diseases, and studies have supported its validity for use with RA patients. ${ }^{14,19}$

This study aims to ascertain the correlation between disease activity measured by DAS28-ESR and physical and mental components of quality of life measured by SF-36 in RA patients.

\section{Research Methods}

This study was an analytical descriptive study with a cross sectional design that took primary data from RA patients who were underwent treatment in Rheumatology Clinic of dr. Hasan Sadikin Hospital in Bandung, from February to May 2015. Sampling was done using consecutive sampling method.

The inclusion criteria were all patients who fulfilled the 2010 American College of Rheumatology/ European League Against Rheumatism (ACR/EULAR) criteria for rheumatoid arthritis, aged above 14 years old, can read and write, and no verbal communication impairment. All participants gave their consent to be enrolled in this study and the study protocol had been approved by the appropriate local ethical board. The exclusion criteria were patients with other diseases manifesting in joints and bone (osteoartritis, psoriatic arthritis, reactive arthritis, ankylosing spondilitis, fibromyalgia, gout arthritis, septic arthritis, and fractures), patients with infections, malignancies, and cardiovascular diseases, and patients with pain originating from areas other than joints.

\section{Assessment}

Study subjects would went through history taking, physical examinations, blood tests, and questionnairefilling. The history taking was done to collect demographic characteristics included age, sex, profession, education level, and marital status. While clinical characteristics collected include the length of time since RA diagnosis, medications taken for the disease, and patients' global assessment to calculate DAS28-ESR score. The medications for RA referred to this study included glucocorticoid and DMARD (methotrexate, leflunomide, cyclosporine, etanercept, and infliximab), based on a systematic review by Blumenauer et al. (2003) about DMARD medications in RA patients. 20 The physical examination was done to collect data on the number of swollen and tender joints which were needed to calculate DAS28-ESR score. The blood test was done to collect the data on patients' serostatus (RF and anti-MCV), and ESR to calculate DAS28-ESR score. Then, the patients were asked to fill in the questionnaires to evaluate their quality of life.

The DAS28-ESR score was calculated with a specific calculator downloaded from the internet, while the serostatus test (RF and anti-MCV) was done using the Rheumachec rapid test (Orgentec Diagnostika GmbH, Mainz, Germany), and the quality of life was evaluated using SF-36 questionnaires.

\section{Statistical Analysis}

Univariate analysis aimed to describe the characteristics of study subjects included age, sex, serostatus (RF and anti-MCV), SF-36 scores, DAS28ESR scores, length of time since RA diagnosis, and number of medications taken for RA, which were presented in number and percentage for categorical data, and mean, standard of deviation, median, minimum and maximum for numerical data. To answer 
the hypothesis about the correlation between disease activity (DAS28-ESR score) and quality of life (SF-36 scores) in RA patients, we used the Rank Spearman correlation analysis. The data analysis was done using the Statistical Product and Service Solution (SPSS) for Windows version 18.0 program on the confidence interval of $95 \%$ and $p$ value of $\leq 0,05$.

\section{Results}

The number of RA patients who went to Rheumatology Clinic in dr. Hasan Sadikin Hospital Bandung from January 2014 to June 2015 was 194 patients, consisting of 171 female patients and 23 male patients. This study was done over 4 months, from February to May 2015. There were 42 patients who fulfilled the inclusion criteria and did not fulfill the exclusion criteria. The baseline characteristics for study subjects are shown in Table $\mathbf{1}$ below. The Shapiro-Wilk test was used to test data normality of each characteristic

Most of the study subjects were female, by a ratio of 20:1 between the number of females and males. The youngest subject was 18 and the oldest was 61 . The fifth decade was the largest group of the study subjects (31\%). The next largest groups were the third and the fourth decades, each being of $19 \%$. The number of study subjects with positive serostatus (positive RF and/or anti-MCV) was more than the study subjects with negative serostatus (negative RF and anti-MCV), was 31 subjects $(73.8 \%)$. There were 8 study subjects (19\%) which had the length of time since RA diagnosis was < 6 months, and 34 study subjects (81\%) which had the length of time since RA diagnosis $\geq 6$ months.
There were 5 study subjects (11.9\%) who did not get glucocorticoid. The data for DAS28-ESR scores and SF36 scores can be seen in Table 2 below.

The results of this study also showed that disease activity in most study subjects (67\%) were moderate, followed by high disease activity in 8 patients (19\%), and low disease activity in 6 patients (14\%). Before analysing the correlation between disease activity score (DAS28-ESR) and physical component of quality of life (SF-36 PCS), a plot was made based on the distribution of data from these two variables, as seen in Figure 1 below. Before analysing the correlation between disease activity score (DAS28-ESR) and mental component of quality of life (SF-36 MCS), a plot was made based on the distribution of data from these two variables, as seen in Figure 2 below. To find the correlation value between DAS28-ESR variable with the physical and mental components of quality of life, the RankSpearman correlation analysis was carried out. The results from the Rank-Spearmen correlation analysis showing the correlation coefficients between the DAS28-ESR score and physical and mental components of quality of life are shown in Table 3 below.

Based on the result of correlation analysis in Table 3 , at 95\% confidence interval, there was a strong negative correlation between DAS28-ESR score and SF36 PCS score $(r=-0.577 ; \mathrm{p}<0.001)$ and a moderate negative correlation between DAS28-ESR score and SF36 MCS score $(r=-0.368 ; \mathrm{p}=0.008)$. These results showed that the higher the DAS28-ESR, the lower the SF-36 PCS and MCS scores, and both correlations were statistically significant

Table 1. The Baseline Characteristics of the Study Subjects

\begin{tabular}{lccc}
\hline \multicolumn{1}{c}{ Characteristic } & $\begin{array}{c}\text { Result } \\
\mathbf{n = 4 2}\end{array}$ & $\begin{array}{c}\text { p value of } \\
\text { normality } \\
\text { test* }\end{array}$ & Description \\
\hline $\begin{array}{l}\text { Sex } \\
\text { Male (\%) }\end{array}$ & $2(4.8)$ & \\
Female (\%) & $40(95.2)$ & \\
$\begin{array}{l}\text { Age (year) } \\
\text { (mean } \pm \text { SD) }\end{array}$ & $41 \pm 12$ & 0.088 & Normal \\
Marital Status & & &
\end{tabular}


Married (\%)

Widowed $(\%)$

Not married $(\%)$

\section{Profession}

Housewife (\%)

Employee of private sector (\%)

Farmer (\%)

Student $(\%)$

Government employee (\%)

Not working (\%)

Education Level

Elementary school (\%)

Junior high school (\%)

Senior high school (\%)

Academy (\%)

University (\%)

\section{Serostatus}

$\mathrm{RF}(+)$ and Anti-MCV (+)

RF (+) and Anti-MCV (-)

RF (-) and Anti-MCV (+)

RF (-) and Anti-MCV (-)

Length of time since RA diagnosis

(month)

(Median (range))

$24(1-216)$

$<0.001$

Not Normal

Number of RA medication

(Median (range))

$$
3(1-4)
$$

$<0.001$

Not Normal

Number of DMARD

(Median (range))
$(7.1)$

$24(57.1)$

5 (11.9)

$1(2.4)$

(7.14)

4 (9.5)

7 (16.7)

20 (47.6)

7 (16.7)

5 (11.9)

9.5)

11 (26.2)
32 (76.2)

*Normality test using Shapiro-Wilk test, data has a normal distribution if $\mathrm{p}>0.05$

Table 2. DAS28-ESR Scores and SF-36 Scores in Study Subjects

\begin{tabular}{lc}
\hline \multicolumn{1}{c}{ Characteristic } & $\begin{array}{c}\text { Result } \\
\mathbf{n = 4 2}\end{array}$ \\
\hline $\begin{array}{l}\text { DAS28-ESR Score } \\
\text { (Median (range)) }\end{array}$ & $4.3(2.2-6.5)$ \\
\hline $\begin{array}{l}\text { SF-36 (PCS) Score } \\
\text { (Median (range)) }\end{array}$ & $39.8(26.4-53.1)$ \\
\hline $\begin{array}{l}\text { SF-36 (MCS) Score } \\
\text { (Median (range)) }\end{array}$ & $48.2(30.1-61.5)$ \\
\hline
\end{tabular}


Figure 1. Scatterplot of Correlation between DAS28-ESR Scores and SF-36 PCS Scores

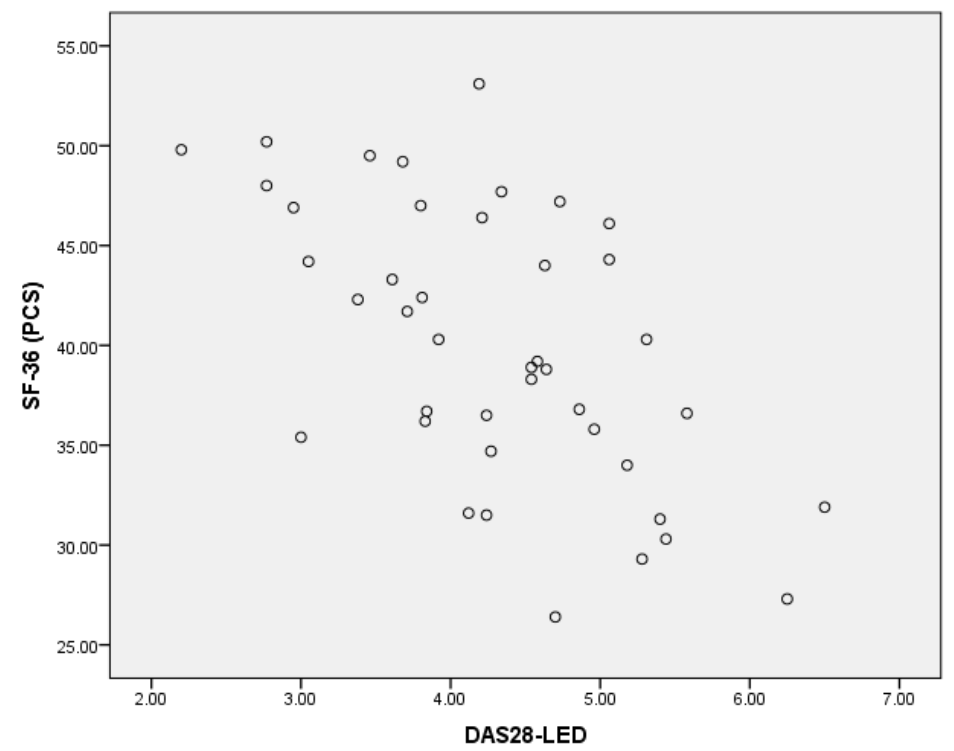

Figure 2. Scatterplot of Correlation between DAS28-ESR Scores and SF-36 MCS Scores

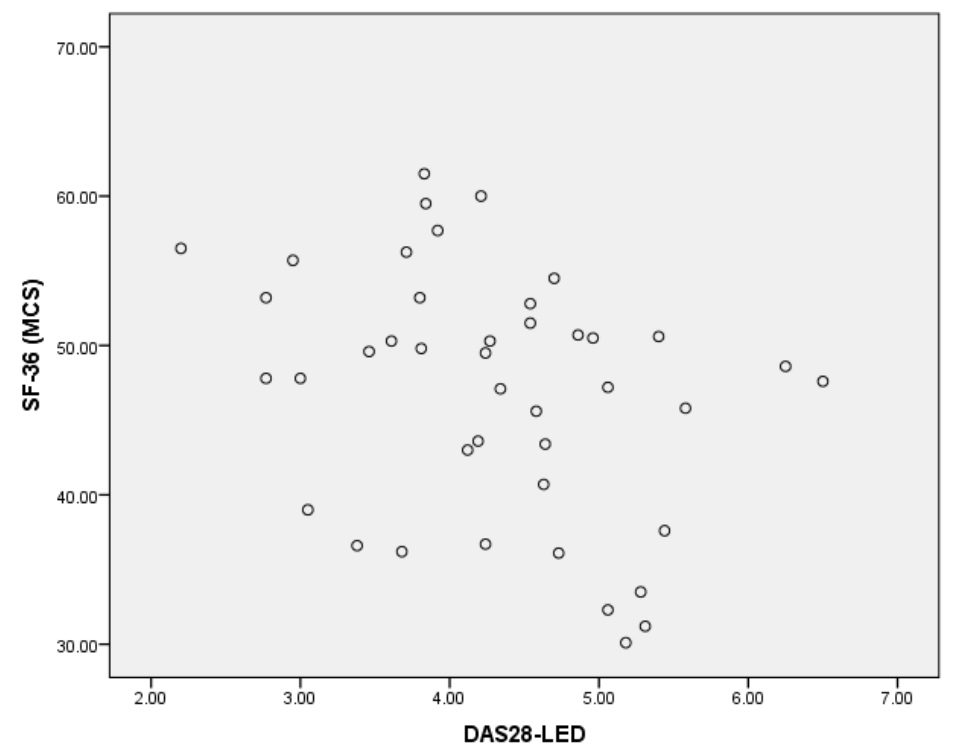

Table 3. Correlation Coefficients between Disease Activity (DAS28-ESR) and Quality of Life (SF-36)

\begin{tabular}{lccc}
\hline & & \multicolumn{2}{c}{ Quality of Life (Skor SF-36) } \\
\cline { 3 - 4 } & & PCS & MCS \\
\hline DAS28-ESR & $r_{\mathrm{s}}$ & -0.577 & -0.368 \\
& $p$ value* & $<0.001$ & 0.008
\end{tabular}

*Note: Analysis using Rank-Spearman correlation, significant if $\mathrm{p}<0,05$ 


\section{DISCUSSION}

The exact cause of higher RA prevalence in females is unknown, but genetic factors (X-linked) and female sex hormones, especially during peri-menopausal period, might play a role. ${ }^{21,22}$ From literature, the ratio between the number of female and male patients is usually around $3: 1$, such as the result from a study by Chen et al. (2007) in Taiwan. ${ }^{13,23}$ Larger ratios were found in other studies, such as 4.5:1 in a study by Lu et al. (2008) in Taiwan, and $5: 1$ in a study by Benitha et al. (2007) in South Africa. 16,24

Regional variations in RA prevalence might be influenced by behavioral factors, climate, environmental exposure, diagnostic approach for RA, and genetic factors. ${ }^{25,26}$ The gender difference in RA is not limited only to prevalence, but also to clinical course and prognosis. ${ }^{27}$ Several differences are associated with differences in clinical presentation, which male patients more often seek medical treatment related to symptoms in spine, while female patients more often seek medical treatment related to symptoms in peripheral joints (such as in RA). ${ }^{28}$ An international chort study (QUEST-RA) done by Sokka et al. (2009) showed higher disease activity and poorer physical function in female patients than male patients. Female patients experienced higher subjective disease activity and DAS28 than male patients. ${ }^{27}$ A study by Smedstad et al. (1995) showed that female gender was associated with a reduction in physical abilities. ${ }^{29}$ Female patients are less strong than male patients, which affects their functional status, so the same burden from musculoskeletal diseases will lead to a worse effect in female patients. ${ }^{27}$ In terms of seeking treatment, a study by Chung et al. (2006) showed that females were significantly associated with the tendency to seek medical attention for hand deformities in RA. ${ }^{30}$

The mean age for study subjects was $41 \pm 12$ year old, with the largest age group those in the fifth decade. The result of our study was similar to most literature which stated the highest RA prevalence is in the fifth decade, which is the period of hormonal change in women.6,13,21 Similar results were also found in other studies, such as by Alishiri et al. (2011) in Iran. ${ }^{31}$ The most significant age groups were the third and fourth decade, each showing 19\%, and our result was also similar to a study result in Australia, which found two peaks of RA prevalence, the third and fifth decade. ${ }^{3}$

According to ACR, early-stage RA is defined as patients with a duration of disease $<6$ months, while late-stage $\mathrm{RA}$ is defined as patients with a duration of disease $\geq 6$ months. ${ }^{32}$ From our study, the majority of patients $(81 \%)$ who came to the clinic were late-stage patients.

From EULAR recommendations, DMARD therapy should be started as early as possible and if the treatment target is not achieved with the first DMARD strategy, switch to another synthetic DMARD or an addition of biologic DMARD is recommended.33 The number of DMARDs combined can reach 2-3 drugs. ${ }^{32}$ From IRA (Indonesian Rheumatology Association) recommendations, all RA patients should also get DMARDs as soon as possible, ideally within 3 months after the symptoms start. Patients with early-onset RA should get DMARDs combination therapy, and if it's not possible, DMARD monotherapy with a rapid dose escalation until clinically effective dose is reached. ${ }^{34}$ From a systematic review by Schoels et al. (2010) on cost-effectivity of RA therapeutic options, the treatment strategy that aimed to maintain the physical function was cost-effective, even when it involved more expensive biologic DMARDs. ${ }^{35}$ Even though there is a significant increase in cost, these drugs can lower the disease activity significantly and decrease the joint damage. 9 From our study, the median number of DMARDs given to the study subjects was still not maximum, with the median of duration diagnosed with RA relatively long (24 months). The number of synthetic DMARDs taken by most study subjects was not the maximum number, and none of the patients were ever administered biologic DMARDs.

Based on previous studies, RF can be detected in 60 - 80\% RA patients. ${ }^{36,37}$ A similar result was found in our study, which RF was positive in 30 study subjects (71.4\%). While for anti-MCV, the prevalence of RA patient in population is still unknown and in this study we only found positive anti-MCV in 6 study subjects 
(14.3\%). The difference in ACPA prevalences across studies can be caused by factors such as genetic (SE HLA-DRß1), behavior such as smoking, test method, the duration of the disease, and therapy. 38,39 Even though the SE alleles are the most noted genetic risk factor for ACPA positivity, the new genetic analysis have detected non-SE-HLA and non-HLA alleles as predisposition for ACPA, such as a few SNP (single nucleotide polymorphism) of PADI4 in Asian populations.6,25,40 Another important risk factor is smoking. Based on study conducted by Klareskog et al. (2002) in Sweden, smoking was associated as a risk factor for RA with positive ACPA only in patients with positive SE. ${ }^{41}$ The level of ACPA was also influenced by therapy, as found in the study by Ally et al. (2015), which synthetic DMARD use was associated with a significant decrease in the ACPA level. 39 In our study, we didn't carry out a genotype test, the history of smoking in the subjects was unknown, and the ACPA test was done with a qualitative method using POCT.

The study results showed that the disease activity in most study subjects was moderate, followed by some subjects had high disease activity, and the other subjects had low disease activity. This result showed that one of the targets in RA management, which had a low disease activity or remission, was still not achieved in most subjects. A similar result was also found in a study by Haroon et al. (2007) in India, with a mean DAS28 score of 4.43 .42 One of the factors is the "treat to target" strategy that is still not fully implemented in our clinic. It might be caused by several factors such as doctors who haven't given RA therapy according to EULAR recommendatios, or factors related to DMARDs use, such as their availability and sustainability. A study result from tREACH (Treatment in the Rotterdam Early Arthritis CoHort), which was presented at the annual congress of EULAR 2015 showed that initial therapy using DMARDs combination significantly improved disease activity and fuctional capacity in early-stage RA, compared to DMARD monotherapy. ${ }^{43}$ In our clinic, the DMARDs haven't been optimally used, where the number and dose of synthetic DMRADs taken by most subjects were probably not of the maximum limit, and these study subjects were never administered biologic DMARDs. Patients' compliance to DMARD therapy also affects their disease activity. A study by Pascual-Ramos et al. (2009) showed that patients who were compliant had a lower DAS28 score and greater improvement in the score during follow-up, and also achieved more long-lasting remission. ${ }^{44}$ The DAS28 score consists of clinical, biochemical, and patient-reported outcomes, so psychological factor can influence the subjective component reported by patients. 45 Based on a study by Kojima et al. (2009), the disease activity components were also associated with symptoms felt by patients and patients' physical function.17 Examples of these symptoms are the duration and severity of morning stiffness and the intensity of pain upon waking up in the morning. 46 From clinical trials, other factors such as structural damage that can be assessed radiologically is also associated with disease activity. ${ }^{47}$ In our study, we didn't take data on patients' compliance, psychological states, current symptoms, physical function, or radiological damage.

From our study, the median score for physical component of quality of life is lower than the median score for mental component of quality of life. A similar result was found in a study by Alishiri et al. (2011) and Salaffi et al. (2009).19,31

Based on the Rank-Spearman correlation analysis, in our study we found a strong negative correlation between disease activity and physical component of quality of life, and a moderate correlation between disease activity and mental component of quality of life. These results showed that the correlation between disease activity with the quality of life is stronger in the physical component, compared to the mental component. Similar results were also found in studies by $\mathrm{Lu}$ et al. in Taiwan and Alishiri et al. in Iran. 16,31 Different results were found in a study by Kwan et al. (2014) and Kojima et al. (2009) which disease activity was not significantly correlated with the quality of life and could not reflect the physical and mental components of the quality of life in RA patients. ${ }^{17,48} \mathrm{In}$ our study, disease activity showed a moderate - strong 
correlation with quality of life, and this might be caused by non-disease-related aspects included in the questionnaires for the quality of life, which are not measured by DAS28 score. The results from previous studies by Van der Heijde et al. (1992) and Chikanza et al. (1994) showed that variables related to disease were strong determinants for physical disability, but not for mental health.49,50 The mechanism for the correlation between DAS28 score and physical component can be caused by the close relationship between disease activity and the extent of inflammation and joint damage, including the degree of clinical disease activity, pain, stiffness, and joint swelling. 31

The difference in correlation significancies between our study and other studies might be caused by differences in the study design, sample size, case definition and selection of subjects, the instruments used in the studies, data presentation, and even culture and language. Because of various limitations, in our study we couldn't examine factors that theoretically can affect quality of life, such as patients' functional capacity, disease perception, degree of fatigue, radiological damage, presence of comorbidities, potential side effects from drugs, coping strategies, social support, degree of helplessness, and existing psychological conditions.

\section{CONCLUSION}

In this study we found a strong negative correlation between disease activity and physical component of quality of life, and a moderate negative correlation between disease activity and mental component of quality of life. Therefore, the higher the disease activity, the lower the physical and mental components of quality of life.

The majority of study subjects were female (95.2\%), in their fifth decade of age (31\%), and had a positive serostatus (RF and/or anti-MCV) (73.8\%). The median score for disease activity was 4.30 (range $2.2-6.5$ ), and most study subjects (67\%) had a moderate disease activity, followed by a high disease activity (19\%), and a low disease activity in 6 study subjects (14\%). The median score for physical component was lower than the median score for mental component of quality of life, that was 39.8 (range 26.4 - 53.1) for physical component and 48.2 (range 30.1 - 61.5) for mental component.

\section{Acknowledgement}

This study was supported by PT. Nelta Multi Gracia by providing Rheumachec rapid test (Orgentec Diagnostika GmbH, Mainz, Germany). We thank Evan Susandi for providing the statistic consultation in the study.

\section{REFERENCES}

1. Dejaco C, Klotz W, Larcher H, Duftner C, Schirmer M, Herold M. Diagnostic value of antibodies against a modified citrullinated vimentin in rheumatoid arthritis. Arthritis Research \& Therapy 2006;8:R119.

2. Centers for Disease Control and Prevention. Rheumatoid Arthritis. [Internet]. 2012 [cited 2014 Mar]; Available from: URL:http://www.cdc.gov/arthritis/basics/rheum atoid.htm

3. Australian Bureau of Statistics. Population by Age and Sex, Regions of Australia. [Internet]. 2011 [cited 2014 Sep]; Available from: URL: http://www.abs.gov.au/ausstats/abs@.nsf/Prod ucts/3235.0 2011 Main+Features Main+Featur es\#PARALINK3

4. Nainggolan O. Prevalence and Determinant of Rheumatic Diseases in Indonesia [Prevalensi dan Determinan Penyakit Rematik di Indonesia]. Medical Journal of Indonesia [Majalah Kedokteran Indonesia] 2009;59(12):588-94.

5. Gibofsky A. Overview of Epidemiology, Pathophysiology, and Diagnosis of Rheumatoid Arthritis. Am J Manag Care 2012;18:S295-302.

6. Tobon GJ, Youinou P, Saraux A. The environment, geo-epidemiology, and autoimmune disease: Rheumatoid arthritis. J Autoimmune 2010;35(1):10-4.

7. Renger F, Bang H, Fredenhagen G, Natusch A, Backhaus M, Feist E, et al. Anti-MCV Antibody Test for the Diagnosis of Rheumatoid Arthritis Using a POCT-Immunoassay. American College of Rheumatology Annual Scientific Meeting, poster presentation. [Internet]. 2008 [cited 2014 Mar]; Available from: URL: https://acr.confex.com/acr/2008/webprogram/ Paper2009.html

8. Aletaha D, Neogi T, Silman AJ, Funovits J, Felson DT, Bingham CO. 2010 Rheumatoid Arthritis 
Classification Criteria: An American College of Rheumatology/European League Against Rheumatism Collaborative Initiative. Arthritis \& Rheumatism 2010;62(9):2569-81.

9. Radner H, Smolen JS, Aletaha D. Remission in rheumatoid arthritis: benefit over low disease activity in patient-reported outcomes and costs. Arthritis Research \& Therapy 2014;16:R56.

10. Fransen J, Stucki G, van Riel PLCM. Rheumatoid Arthritis Measures. Arthritis \& Rheumatism 2003;49(5S):S214-24.

11. Symmons DPM. Rheumatoid arthritis: assessing disease activity and outcome. Clinical Medicine 2010;10(3):248-51.

12. Farheen K, Agarwal SK. Assessment of Disease Activity and Treatment Outcomes in Rheumatoid Arthritis. Supplement to Journal of Managed Care Pharmacy 2011;17(9-b):S9-S13.

13. Iskandar A, Wachjudi RG. The Diagnosis and Principle of Management in Rheumatoid Arthrtis [Diagnosis dan Prinsip Penatalaksanaan Artritis Reumatoid]. In: Proceedings of the 2014 Bandung Clinical Rheumatology Scientific Meeting [Himpunan Makalah Lengkap Reumatologi Klinik Bandung 2014]; Bandung: Pusat Informasi Ilmiah, Departemen Ilmu Penyakit Dalam, Fakultas Kedokteran UNPAD, RS Dr Hasan Sadikin; 2014. p. 309-40.

14. Daul P, Grisanti J. Monitoring Response to Therapy in Rheumatoid Arthritis. Bull NYU Hosp Jt Dis 2009;67(2):236-42.

15. Karimi S, Yarmohammadian MH, Shokri A, Mottaqhi P, Qolipur K, Kordi A, et al. Predictors and effective factors on quality of life among Iranian patients with rheumatoid arthritis. Mater Sociomed 2013;25(3):158-62.

16. Lu SR, Lin HY, Lin KC, Lin HR. Quality of life in middle-aged and older Taiwanese patients with rheumatoid arthritis. J Nurs Res 2008;16(2):12130.

17. Kojima M, Kojima T, Ishiquro N, Oguchi T, Oba M, Tsuchiya $\mathrm{H}$, et al. Psychososial factors, disease status, and quality of life in patients with rheumatoid arthritis. $\mathrm{J}$ Psychosom Res 2009;67(5):425-31.

18. Welsing PMJ, van Gestel AM, Swinkels HL, Kiemeney LA, van Riel PL. The Relationship Between Disease Activity, Joint Destruction, and Functional Capacity Over the Course of Rheumatoid Arthrtis. Arthritis \& Rheumatism 2001;44(9):2009-17.

19. Salaffi F, Carotti M, Gasparini S, Intorcia M, Grassi W. The health-related quality of life in rheumatoid arthritis, ankylosing spondylitis, and psoriatic arthritis: a comparison with a selected sample of healthy people. Health and Quality of Life Outcomes 2009;7(1):25.
20. Blumenauer B, Cranney A, Clinch J, Tugwell P. Quality of life in patients with rheumatoid arthritis: which drugs might make a difference?. Pharmacoeconomics 2003;21(13):927-40.

21. Phe A. Rheumatoid Arthritis: Arthritis and Musculoskeletal Conditions in Australia 2005. [Online]. 2005 [cited 2014 Sep]; Available from: URL:

http://www.aihw.gov.au/WorkArea/DownloadAs set.aspx?id $=6442459675$

22. Van Vollenhoven RF. Sex differences in rheumatoid arthritis: more than meets the eye. BMC Medicine 2009;7:12.

23. Chen HA, Chen WS, Wang HB, Su GY, Chou CT. The treatment of anti-cyclic citrullinated peptide antibody in rheumatism. Clinical Medicine 2007;59(2):97-101.

24. Benitha R, Tikly M. Functional disability and health-related quality of life in South Africans with rheumatoid arthritis and systemic lupus erythematosus. Clin Rheumatol 2007;26:24-29.

25. Firestein GS. Etiology and Pathogenesis of Rheumatoid Arthritis. Kelley's Textbook of Rheumatology. 9th ed. Philadephia: Elsevier; 2012. p. 1035-86.

26. Carmona L, Cross M, Williams B, Lassere M, March L. RA; Rheumatoid Arthritis. Rheumatoid Arthritis. Best Practice \& Research Clinical Rheumatology 2010;24(6):733-45.

27. Sokka T, Toloza S, Cutolo M, Kautiainen $\mathrm{H}$, Makinen H, Gogus F, et al. Women, men, and rheumatoid arthritis: analyses of disease activity, disease characteristics, and treatments in the QUEST-RA study. Arthritis Research \& Therapy 2009;11.R7.

28. Ullman K. The Gender Effect. [Internet]. 2009 [cited 2015 Jul]; Available from: URL: http:/ / www.the-rheumatologist.org/article/thegender-effect $/ 4$ /?singlepage $=1$

29. Smedstad LM, Kvien TK, Moum T, Vaglum P. Life events, psychosocial factors, and demographic variables in early rheumatoid arthritis: relations to one-year changes in functional disability. $J$ Rheumatol 1995;22(12):2218-25.

30. Chung KC, Kotsis SV, Kim HM, Burke FD, Wilgis EF. Reasons why rheumatoid arthritis patients seek surgical treatment for hand deformities. J Hand Surg Am 2006;31(2):289-94.

31. Alishiri GH, Bayat N, Salimzadeh A, Salari A, Hosseini SM, Rahimzadeh S, et al. Health-related quality of life and disease activity in rheumatoid arthritis. J Res Med Sci 2011;16(7):897-903.

32. Singh JA, Furst DE, Bharat A, Curtis JR, Kavanaugh AF, Kremer JM, et al. 2012 Update of the 2008 American College of Rheumatology Recommendations for the Use of DiseaseModifying Antirheumatic Drugs and Biologic 
Agents in the Treatment of Rheumatoid Arthritis. Arthritis Care \& Research 2012;64(5):625-39.

33. Smolen JS, Landewe $\mathrm{R}$, Breedveld FC, Buch $\mathrm{M}$, Burmester $G$, Dougados $M$, et al. EULAR recommendations for the management of rheumatoid arthritis with synthetic and biological disease-modifying antirheumatic drugs: 2013 update. Ann Rheum Dis 2013;0:1-18.

34. Perhimpunan Reumatologi Indonesia. Rekomendasi untuk Diagnosis dan Pengelolaan Artritis Reumatoid [Recommendations on Diagnosis and Management of Rheumatoid Arthritis]. Jakarta: Perhimpunan Reumatologi Indonesia; 2014.

35. Schoels M, Wong J, Scott DL, Zink A, Richards P, Landewe $\mathrm{R}$, et al. Economic aspects of treatment options in rheumatoid arthritis: a systematic literature review informing the EULAR recommendations for the management of rheumatoid arthritis. Ann Rheum Dis 2010;69:996-1004.

36. Egerer K, Feist E, Burmester G. The Serological Diagnosis of Rheumatoid Arthritis: Antibodies to Citrullinated Antigens. Deutsches Arzteblatt International 2009;106(10):159-63.

37. Roland PN, Mignot SG, Bruns A, Hurtado M, Palazzo E, Hayem G, et al. Antibodies to mutated citrullinated vimentin for diagnosing rheumatoid arthritis in anti-CCP-negative patients and for monitoring infliximab therapy. Arthritis Research \& Therapy 2008;10:R142.

38. Kim H. Anti-citrullinated protein antibodies in rheumatoid arthritis: a bridge between genetic predisposition and autoimmunity. Korean J Intern Med 2013;28:25-28.

39. Ally MMTM, Hodkinson B, Meyer PWA, Musenge E, Tintinger GR, Tikly M. Circulating anticitrullinated peptide antibodies, cytokines and genotype as biomarkers of response to diseasemodifying antirheumatic drug therapy in early rheumatoid arthritis. BMC Musculoskeletal Disorders 2015;16:130-8.

40. Song YW, Kang EH. Autoantibodies in rheumatoid arthritis: rheumatoid factors and anticitrullinated protein antibodies. Q J Med 2010;103:139-46.

41. Klareskog L, Stolt P, Lundberg K, Kallberg H, Bengtsson C, Grunewald J, et al. A new model for an etiology of rheumatoid arthritis: smoking may trigger HLA-DR (shared epitope)-restricted immune reactions to autoantigens modified by citrullination. Arthritis Rheum 2002;47:403-7.

42. Haroon N, Aggarwal A, Lawrence A, Agarwal V, Misra R. Impact of rheumatoid arthritis on quality of life. Mod Rheumatol 2007;17:290-5.

43. De Jong PH, Hazes JM, Barendregt PJ, Huisman $M$, van Zeben $D$, van der Lubbe PA, et al. Induction therapy with a combination of DMARDs is better than methotrexate monotherapy: first results of the tREACH trial. Ann Rheum Dis 2013;72(1):728.

44. Pascual-Ramos V, Contreras-Yanez I, Villa AR, Cabiedes J, Rull-Gabayet M. Medication persistence over 2 years of follow-up in a cohort of early rheumatoid arthritis patients: associated factors and relationship with disease activity and with disability. Arthritis Research \& Therapy 2009;11:R26.

45. Cordingley L, Prajapati R, Plant D, Maskell D, Morgan C, Ali FR, et al. Impact of psychological factors on subjective disease activity assessments in patients with severe rheumatoid arthritis. Arthritis Care Res 2014;66(6):861-8.

46. Boers M, Buttgereit F, Saag K, Alten R, Grahn A, Storey $\mathrm{D}$, et al. What is the relationship between morning symptoms and measures of disease activity in patients with rheumatoid arthritis?. Arthritis Care Res. 2015 Mar. doi: 10.1002/acr.22592. [Epub ahead of print]

47. Van der Heijde D. Radiographic progression in rheumatoid arthritis: Does it reflect outcome? Does it reflect treatment?. Ann Rheum Dis 2001;60:iii47-50.

48. Kwan YH, Koh ET, Leong KP, Wee HL, Tan Tock Seng Rheumatoid Arthritis Study Group. Association between helplessness, disability, and disease activity with health-related quality of life among rheumatoid arthritis patients in a multiethnic Asian population. Rheumatol Int 2014;34(8):1085-93.

49. Van der Heijde DM, Van't Hof MA, Van Riel RL, Van Leeuwen MA, Van Rijswijk MH, Van de Putte LB, et al. Validity of single variables and composite indices for measuring disease activity in rheumatoid arthritis. Ann Rheum Dis 1992;51(2):177-81.

50. Chikanza IC, Stein M, Lutalo S, Gibson T. The clinical, serologic and radiologic features of rheumatoid arthritis in ethnic black Zimbabwean and British Caucasian patients. J Rheumatol 1994;21(11):2011-5. 